\title{
Work in Progress - Establishing a Master Program in Cyber Physical Systems: Basic Findings and Future Perspectives
}

\author{
Isam Ishaq ${ }^{1}$, Rashid Jayousi ${ }^{1}$, Salaheddin Odeh ${ }^{1}$, Ezzaldeen Edwan ${ }^{2}$, Asmaa Shaheen ${ }^{2}$, Mohamed Elnaggar ${ }^{2}$, \\ Ahmed Elagha ${ }^{2}$, Samy Salamah ${ }^{2}$, Christian Weber ${ }^{3}$, Hasan Abu Rasheed ${ }^{3}$, Raimund Kirner ${ }^{4}$, Martina Doolan ${ }^{4}$, \\ Hamidreza Ahmadian ${ }^{5}$, Roman Obermaisser ${ }^{5}$, Dhiah el Diehn I. Abou-Tair ${ }^{6}$, Ala Khalifeh ${ }^{6}$, Sahel Alouneh ${ }^{6}$, \\ Zaid Alhalhouli ${ }^{7}$, Khalid Alemerien ${ }^{7}$, Faiez Gargouri ${ }^{8}$, Bassem Bouaziz ${ }^{8}$, Nadia Aloui ${ }^{9}$, Mohammad Saleh $^{10}$ \\ ${ }^{1}$ Computer Engineering and Science Departments; Al-Quds University, Jerusalem, Palestine \\ ${ }^{2}$ Engineering Program and Computer Department, Palestine Technical College - Deir El-Balah, Deir El-Balah, Palestine \\ ${ }^{3}$ Institute of Knowledge Based Systems \& Knowledge Management, University of Siegen, Siegen, Germany \\ ${ }^{4}$ School of Engineering and Computer Science, University of Hertfordshire, Hatfield, UK \\ ${ }^{5}$ Chair of Embedded Systems, University of Siegen, Siegen, Germany \\ ${ }^{6}$ School of Electrical Engineering and Information Technology, German Jordanian University, Amman, Jordan \\ ${ }^{7}$ Computer and Information Technology Department, Tafila Technical University, Tafila, Jordan \\ ${ }^{8}$ Higher Institute of Computer Science and Multimedia, University of Sfax, Sfax, Tunisia \\ ${ }^{9}$ Higher Institute of Applied Sciences and Technology of Mateur, University of Carthage, Mateure, Tunisia \\ ${ }^{10}$ KTH Royal Institute of Technology, Stockholm, Sweden
}

\begin{abstract}
This paper reports on the basic findings and future perspectives of a capacity building project funded by the European Union. The International Master of Science on Cyber Physical Systems (MS@CPS) is a collaborative project that aims to establish a master program in cyber physical systems (CPS). A consortium composed of nine partners proposed the project. Three partners are European and from Germany, UK and Sweden; while the other six partners are from the South Mediterranean region and include: Palestine, Jordan and Tunisia. The consortium is led by the University of Siegen in Germany who also manages the implementation of the work packages. CPS is an emerging engineering subject with significant economic and societal implications, which motivated the consortium to propose the establishment of a master program to offer educational and training opportunities at graduate level in the fields of CPS. In this paper, CPS as a field of study is introduced with an emphasis on its importance, especially with regard to meeting local needs. A brief description of the project is presented in conjunction with the methodology for developing the courses and their learning outcomes.
\end{abstract}

Keywords-Master Program; Curriculum Development; Cyber Physical Systems;

\section{INTRODUCTION}

Cyber physical systems (CPS), is a term which was coined by Dr. Helen Gill at the U.S. National Science Foundation, to describe physical, biological, and engineered systems whose operations are integrated, monitored, and/or controlled by a computational core. Components in such systems are not only networked at every scale, moreover, the computing is "deeply embedded" into every physical component, possibly even into materials[1]. CPS are engineered systems that are built from, and depend upon, the seamless integration of computational algorithms and physical components [2]. The multidisciplinary subject tackles the integration process between the various software and hardware technologies, while maintaining a user friendly and secure human computer environment [3]. Common examples of CPS include smart grid and autonomous automobile systems. Mobile CPS incorporate smartphones were the network connectivity links the mobile system to either cloud computing or a server [4]. CPS is also similar to the Internet of things. The proliferation of CPS highlights a need to educate students and help them develop the necessary skills to respond to, and design the next generation CPS solutions; to meet the demand of the globalized labor market, foster innovation and develop student talents as the mobility readiness and complex system solution handling is a valued skill in a globalized working world. Industrial demand for CPS skills from the perspectives of industry experts were captured via a series of workshops [2], findings noted include: CPS as an emerging engineering subject, has a significant economic and societal implications for industries such as transportation, medicine, defense and tech companies. Also highlighted is the increased demands for different types of engineering and computing graduates, who will join the workforce and capable of creating, designing and combining computing hardware and software aspects with physical segments and equipped with the capacity to manage their interactions and impact on the physical environment.

With this backdrop, the University of Hertfordshire in the United Kingdom whilst developing their bachelor's and master's degrees carefully and thoughtfully considered how best to incorporate CPS into the computer science curricula. The rationale was to help students to develop the knowledge and associated skills required to engineer cyber physical systems through a series of practical hands-on lab-based activities incorporating a problem-based learning pedagogy including traditional lectures and instructional materials for subject delivery by adopting a constructive alignment approach. This means that teaching and learning activities were purposively designed and assessed, to ensure the alignment of knowledge and skills appropriate to achieve the desired learning outcomes [5]. Academic staff at the University of Hertfordshire participating in the MS@CPS project design lectures and practical laboratory exercises such that they are synchronized, which ensures that students explicitly practice the concepts that are lectured. The assessment is done by a practical application, requiring 
students to submit two different coursework projects, each consisting of a computer program for a robot car and a report that describes a solution to the given problem. In addition to the submission of the coursework, it is compulsory for students to attend a demonstration where they demonstrate their implementation and are questioned on their necessary understanding of their submitted solution. In this way, students are relatively free to collaborate with other students in teams but they have to demonstrate their own individual mastery of the subject. The first coursework is designed to be relatively simple to get students started with programming the platform and contains a competition element that motivates them to experiment with different ideas to improve their performance. In this way, students learn a lot about the practical aspects of their first coursework, as they have to analyze reasons for the given system behavior and improve it along with the theoretical knowledge from the associated given lectures. In the second coursework, students are required to develop a more advanced system based on the autonomous car.

Industrial applications of CPS cannot be designed, understood or integrated, neglecting the imminent need for extending the concept of cyber physical systems to intelligent systems and artificial intelligence driven systems (AI). The rise of AI is closely connected to the advent of big data, emerging through incorporating and tracing complex, interconnected and service driven systems, to finally build smarter environments, as captured in the concepts of the $4^{\text {th }}$ industrial revolution. In the intersection of computational algorithms and physical components [2], data driven approaches yield the potential to intersect the state of CPS with historical data and data analytics to enable a real time feedback and reconfiguration of CPS. This is conceptualized using the $5 \mathrm{C}$ model [6], collecting data from CPS, filtering and processing it to usable information, fusing sources and enabling prediction of future states, leading to knowledge about a specific system. Based on that knowledge, decisions can be derived and fed back as lessons learned or configurations of futures system states. To create, support and conceptualize such pipelines, the use of knowledge has to be managed, leading to an imminent need of data-driven, AI focused knowledge technologies, as present in the concepts of knowledge management but in close intersection with the concepts of CPSs.

The University of Siegen has a long running experience of combining embedded systems, as the overarching concept for CPS, knowledge management and intelligent systems, to continuously utilize the intersection for research and teaching throughout the master's degree domains of computer science and electrical engineering. In consideration of the implemented best practices at the University of Siegen, a jointly developed pedagogy is in focus of the MS@CPS master program. The pedagogical design targets the development of student and industrial application centered learning/teaching strategies for new challenges of the MS@CPS profession. As such, it is based on a strong projectand practice-orientation and aims at context-specific qualifications, credit mobility, and flexible curricula to strengthen employability firstly on local and secondly on international markets.
Joint learning projects are in the center, built on training and leveraging complementary expertise, collaborative learning, individual contribution, individualized and self-organized learning, idea generation, fusion and co-creativity, and continuous utilization and exploitation. The pedagogical design will be focusing on the development of team-based and project-oriented learning/teaching strategies to simulate the practical implementation of mixed teams, bringing single competencies for CPS to the table for a given task. This is conceptualized under the new title of Courses in Practice (CiP), targeting the identified, novel challenges of the CPS domain; and incorporating technologies such as mobile/distributed computing, sensor networks, system design, semantic technologies, machine learning, knowledge engineering, advanced analytics, big data and the adaptive development of distributed system solution.

\section{RELATED WORKS AND SIMILAR PROGRAMS}

\section{A. Related literature reporting on establishing master programs}

In the literature, one can find several papers reporting the experiences, methodology and findings of establishing educational master programs in different fields. In [6], the researchers report on the design of a master program on microwave communication with a focus on innovation. They conclude that incorporating a wide spectrum of modern practical skills in engineering physics and innovation management has proved to be attractive to students regardless of negative social and economic tendencies [6]. In [7], the authors report on developing a double degree bilingual Master's program entitled "social work in industry" between partners in Russia and Spain. Their experience reveals a number of difficulties in establishing a double master's program between both countries. These are not only formal differences between degree duration, but the number of credits and program languages. What is more important is to find out common interests that would make this complex process worth conducting [7]. According to the authors, participation in the project allowed the members to gain a new perspective on their own higher education systems, critically evaluate the contents of the existing master's programs and define opportunities for future collaboration. In [8], the authors describe a technique for master's program design developed from the consolidated experience of the leading European and Russian universities. In [9], the authors describe a methodology to implement a collaborative master level course in computer science. Their work is part of a joint project, under the European Union's Lifelong Learning Curriculum Development.

\section{B. The state-of-the-art educational CPS programs}

The idea of establishing courses in CPS is not new. Cheng in [10] describes the development of an upper-division course introducing undergraduates to the fundamentals of cyber physical systems that are a combination of embedded computers, control theory, sensor and communication networks, physical resources, decision theory, data fusion, knowledge discovery, resilience, and dynamic configuration. 
It was apparent that it is not enough to study each of the mentioned components in isolation, since CPS is not their union but their intersection. In other words, their joint dynamics must be studied together; and this is what differentiates this emerging discipline from those individually established fields.

Riga Technical University, which is the only polytechnic university in Latvia and the largest university in the country, succeeded within the cooperation with EU partners in the ERASMUS+ project to bypass one of the important challenges in the development of cyber physical systems curriculum by bridging the gap between industry needs and educational output, in terms of training the prospective researchers and engineers in the CPS field [11].

In [12], the critical importance of system engineering skills for the engineers of cyber physical systems is described with the objective of developing a system engineering of CPS program targeting practice, embedded and CPS engineers. In order to highlight the educational challenge and opportunities in cyber physical systems, the state of embedded CPS development projects was studied.

Nowadays, there are multiple research groups and master programs concentrating on many aspects of CPS. Internationally, graduate certificate programs in cyber physical systems are more available since the importance of this field has been growing during the last years. Table I summarizes some examples of international Master programs in cyber physical systems along with their focus. It is noted that these programs are interdisciplinary and combine knowledge from the fields of embedded systems, networking, sensors, real-time systems and control as well as domain-specific knowledge to realize systems that are of untapped complexity and scale.

TABLE I. EXAMPLES OF INTERNATIONAL MASTER PROGRAMS ON CPS

\begin{tabular}{|c|c|c|c|c|}
\hline $\begin{array}{l}\text { Name of } \\
\text { the Master } \\
\text { Program } \\
\text { or research } \\
\text { group }\end{array}$ & $\begin{array}{l}\text { Educational } \\
\text { Institution }\end{array}$ & Country & Focus & Ref \\
\hline $\begin{array}{l}\text { Cyber } \\
\text { Physical } \\
\text { Systems }\end{array}$ & $\begin{array}{l}\text { University } \\
\text { of Oxford }\end{array}$ & UK & $\begin{array}{l}\text { Intelligent and } \\
\text { autonomous sensor } \\
\text { systems with } \\
\text { applications in } \\
\text { positioning, } \\
\text { healthcare, } \\
\text { environmental } \\
\text { monitoring and smart } \\
\text { cities. }\end{array}$ & [13] \\
\hline $\begin{array}{l}\text { Cyber- } \\
\text { Physical } \\
\text { and Social } \\
\text { Systems }\end{array}$ & $\begin{array}{l}\text { MINES } \\
\text { Saint- } \\
\text { Étienne }\end{array}$ & France & $\begin{array}{l}\text { Artificial Intellegence } \\
\text { and Internet of } \\
\text { Things aimed at } \\
\text { developing } \\
\text { theoretical models } \\
\text { and technologies for } \\
\text { current and future } \\
\text { applications in } \\
\text { industry and society. }\end{array}$ & [14] \\
\hline $\begin{array}{l}\text { Mechatroni } \\
\text { c and } \\
\text { Cyber- } \\
\text { Physical } \\
\text { Systems }\end{array}$ & $\begin{array}{l}\text { Deggendorf } \\
\text { Institute of } \\
\text { Technology }\end{array}$ & Germany & $\begin{array}{l}\text { Enabling graduates of } \\
\text { Mechatronics and } \\
\text { related fields of study } \\
\text { to deepen their } \\
\text { knowledge of } \\
\text { networked systems in } \\
\text { digital production. }\end{array}$ & [15] \\
\hline
\end{tabular}

\begin{tabular}{|c|c|c|c|c|}
\hline $\begin{array}{l}\text { Industrial } \\
\text { Informatics } \\
: \\
\text { Specializati } \\
\text { on } \\
\text { Industrial } \\
\text { Cyber- } \\
\text { Physical } \\
\text { Systems }\end{array}$ & $\begin{array}{l}\text { Hochschule } \\
\text { Emden - } \\
\text { Leer } \\
\text { (University } \\
\text { of Applied } \\
\text { Sciences) }\end{array}$ & Germany & $\begin{array}{l}\text { Special topics } \\
\text { pertaining to the } \\
\text { application of } \\
\text { electrical engineering } \\
\text { and computer } \\
\text { science, focusing on } \\
\text { automation systems, } \\
\text { robotics and } \\
\text { mechatronics, } \\
\text { embedded systems, } \\
\text { modelling and } \\
\text { visualization, network } \\
\text { technologies and } \\
\text { security concepts. }\end{array}$ & [16] \\
\hline $\begin{array}{l}\text { The } \\
\text { Professiona } \\
1 \text { Master of } \\
\text { Embedded } \\
\text { and Cyber- } \\
\text { physical } \\
\text { Systems }\end{array}$ & $\begin{array}{l}\text { University } \\
\text { of California }\end{array}$ & USA & $\begin{array}{l}\text { Training students in } \\
\text { the foundation, skills } \\
\text { and hands-on } \\
\text { practices of } \\
\text { embedded and cyber- } \\
\text { physical systems } \\
\text { design, optimization } \\
\text { and evaluation in the } \\
\text { context of } \\
\text { applications such as } \\
\text { automotive and } \\
\text { transportation, } \\
\text { manufacturing, power } \\
\text { distribution grid etc. }\end{array}$ & [17] \\
\hline $\begin{array}{l}\text { HSE } \\
\text { Tikhonov } \\
\text { Moscow } \\
\text { Institute of } \\
\text { Electronics } \\
\text { and } \\
\text { Mathematic } \\
\text { s (MIEM } \\
\text { HSE) }\end{array}$ & $\begin{array}{l}\text { Internet of } \\
\text { Things and } \\
\text { Cyber- } \\
\text { physical } \\
\text { Systems }\end{array}$ & Russia & $\begin{array}{l}\text { Engineering in the } \\
\text { field of the Internet of } \\
\text { Things and cyber- } \\
\text { physical system, Data } \\
\text { analysis and } \\
\text { application software } \\
\text { in the Internet of } \\
\text { things and cyber- } \\
\text { physical systems and } \\
\text { Cyber security in the } \\
\text { Internet of things }\end{array}$ & [18] \\
\hline
\end{tabular}

\section{LOCAL NEED OF EDUCATIONAL CPS PROGRAMS}

\section{A. Need for the program in Jordan}

To investigate the need for the CPS master program in Jordan, several meetings were conducted with the responsible persons in the private and governmental sectors, as well as with university professors. The meetings were launched in collaboration between Tafila Technical University (TTU) and German Jordan University (GJU). The meetings were designed to present the main objectives of the project, the preliminary suggested topics of the master program and to gather valuable feedback from those experts in attendance.

The meetings in Jordan revealed that the CPS specialization is unique according to the perspectives of the participants from the different sectors. Furthermore, they affirmed a favorable future for the program in accordance with the existing developments in technology. Nowadays, students are characterized by farsightedness and high awareness. The participating experts believe that promotions and holding meetings in many universities and in different sectors will attract students to join this program. Additionally, the academic experts focused on the choice of the program topics and their impact on the strength and sustainability of the program. On the other side, companies' experts pointed out that the available positions for graduates of this program are limited within the current structures. 


\section{B. Need for the program in Palestine}

The importance of the Information and Communication Technology (ICT) sector to the Palestinian national economy was pointed out by the Palestinian ICT Private Sector 3-Year Strategy and Development Plan [19], which has been prepared by the Palestinian Information Technology Association (PITA). The plan stressed the fact that university curricula are not compatible with market needs and requires upgrades. Moreover, there is a need for continuous skill development to keep up with international trends. These findings and needs were confirmed in 2014 by Spark in their report about the Palestinian education system vs. the needs of ICT private sector [20]. Both studies stipulated that university ICT programs should be upgraded and modernized to match emerging global trends. However, to the best of our knowledge, there are no specific studies about the relevance of a CPS or an IoT program to the Palestinian market. In order to assess the need for the program in Palestine, two workshops involving key representatives of the private sector and related university professors were conducted. One workshop was conducted at Al-Quds University's main campus in Abu Dies and the other in Palestine's Technical College - Deir El-Balah. The aim of the workshops was to introduce the preliminary suggested topics of the program and to obtain feedback from the participants about its relevance to the local market. Both workshops concluded that although a CPS specialization is new to the participating companies, the need for such a specialization is expected to increase overtime. The participants believed that offering this specialization as a Master program can be attractive to students but only if promoted in a proper way. Some students might find it risky to specialize in CPS, given the low market demand at the moment. Students applying would be pioneers who are aware of market and technology change. For the companies, CPS graduates would fit in to different but limited positions, within their current structures.

\section{Need for the program in Tunisia}

In order to assess the need for the program in Tunisia, a peer to peer meeting and one workshop was conducted, involving key representatives from the private sector and related University of Sfax and Tunisia professors. In addition to, key experts from government and the information and communication technologies sector. Starting from preliminary suggested topics and collected feedback, Tunisian partners agreed that the CPS specialization will converge with the "Smart Tunisia" initiative [21] by boosting the offshoring sector, through the provision of incentive mechanisms allowing the convergence of supply and demand for employment. This initiative aims to create globally more than 50,000 jobs in the period 2016-2020; and raise Tunisia as a hub of offshoring and a platform of skills for Europe, Africa and the Middle East.

For the local market, the introduction of the CPS specialization is encouraged by the Tunisian initiative of smart cities. Consequently, local private companies are actually working in various fields of smart cities by providing innovative applications in energy, tourism, health, security, etc. Students involved in the local meeting showed interest in the curricula structure, especially the artificial intelligence and embedded systems related modules.

\section{MS@CPS PROJECT IN BRIEF}

With the increasing importance of CPS knowledge for graduates, universities from European countries collaborate with universities from partner countries in Jordan, Palestine, and Tunisia to deliver a modern curriculum for teaching CPS in the partner countries' universities.

\section{A. The Consortium}

Institutions of the program countries include the University of Siegen in Germany, University of Hertfordshire in the UK, and the KTH Royal Institute of Technology in Sweden. Institutions from the partner countries include the German Jordan University and Tafila Technical University from Jordan, Carthage University and the University of Sfax from Tunisia, as well as Al-Quds University and Palestine Technical College - Deir El-Balah from Palestine. Logos of partner universities are shown in Figure1.

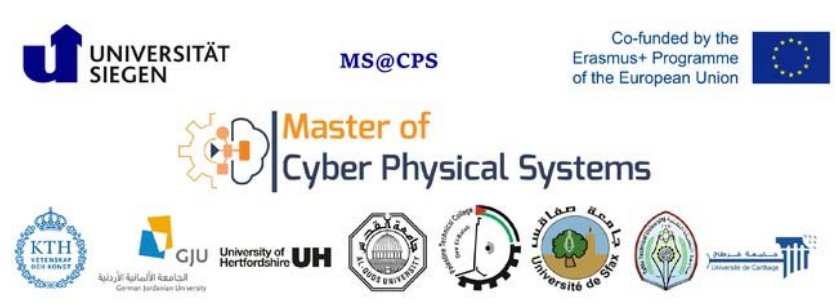

Figure 1: The logos of partner universities

\section{B. Goals of MS@CPS Project}

The main goal of MS@CPS is to establish the complete Master program in CPS. What follows is a list of the procedures that make the established program successful. MS@CPS will provide expertise of primary focus areas: embedded systems and knowledge-based systems, for the industry in program and partner countries, increasing the mobility, capacities and advance knowledge, skills, and competencies in the fields of CPS. Moreover, it will develop pedagogical methods to control the teaching tracks, to implement learning outcomes and to achieve a high level of knowledge, skills, and competencies in practice, in order to create top talent in the field. Conducting training courses for faculty members and staff is essential in capacity building. It is intended to develop technical courses that meet the market needs. The participants will define the program admission policies and deal with institutional regulations and national accreditation policies. The targeted students will be identified based on quantitative and qualitative analysis of the market needs. Establishing advanced laboratories in the project partner universities, equipped with the latest technology of hardware and software tools is another important element in the capacity building process. Economic entrepreneurship, in which management skills will be conveyed as required for enabling graduate student to establish startups and strengthen industry. Dual studies, involving companies in internships and master thesis work performed in collaboration with industry will be implemented. Enhancing international 
mobility and job opportunities can be achieved through the alignment between partner and program countries.

\section{Structure of MS@CPS Project Work Packages}

To implement the project, we followed the classical work packages structure of Erasmus plus projects. The first work package, as a preparation work package, aims to evaluate the existing courses at each consortium partner, in order to identify the needed courses and expertise, locate the current and future market requirements to ensure that program outcomes meet the market requirements; and to identify any shortcomings of courses or expertise in the field. The second work package is devoted to planning and developing the curricula. The third work package focuses on developing an innovative partnership model to foster cooperation between universities and enterprises. The fourth work package is dedicated for using best practices and standards in the field of quality assurance. Dissemination and exploitation activities are dealt with in work package five. Exploitation activities include the accreditation of the program and its deployment at consortium universities. This work package also includes the project events and the project's sustainability plan. Management and coordination of the program issues are organized in work package six.

\section{Methodology for CURRICULUM DEVElopment}

In order to explore the existing computer science programs that are related to the CPS program, two surveys were designed. The purpose of the surveys is to help the identification of potential courses and program structures in every partner country, where the program is to be implemented [22]. The survey contained four sections: potential courses, market requirement, courses and staff expertise, and program structure and future prospective. The first section contained two parts: the first lists the courses that are related to CPS program, where partners were asked to indicate if such courses exist in one of the programs offered in their country. Partners were also asked to state what expertise for teaching such courses is available. The second part contains a table of extra potential courses that do not exist in the first part. In this survey, the second section was intended for market analysis. The third section was intended to identify the needed capacity building requirements at partner institutes, in order to effectively implement the program. All partners were asked to fill an additional table for similar programs around the world to learn more about existing CPS programs and benefit from them. These surveys were analysed and compared with existing CPS programs in different countries. The results of the analysis proposed main potential courses for the program. Accordingly, the list of courses was refined, discussed and reviewed by all partners; and then the partners concluded with a list of core courses and a structure of the intended program.

\section{ANALYSIS OF PRELIMINARY FINDINGS}

In preparation for this step, partners in Jordan, Palestine, and Tunisia worked on involving the private sector and related university professors in reviewing the draft curriculum; capturing their feedback and establishing a base for further engagement in the development of both program curriculum and courses contents. After reviewing the input of all partner countries, comparing it with the existing programmes worldwide, and collecting the feedback from the private sector, the findings were summarised in Table II below which shows the identified core and elective courses.

TABLE II. INITIAL LIST OF PROPOSED CORE AND ELECTIVE COURSES

\begin{tabular}{|c|c|c|}
\hline & Core Courses & Elective Courses \\
\hline 1 & Internet of Things & $\begin{array}{l}\text { Advanced Computational } \\
\text { Modelling and Analysis }\end{array}$ \\
\hline 2 & $\begin{array}{l}\text { Artificial Intelligence and } \\
\text { Multiagent Systems }\end{array}$ & Basics of SCADA Systems \\
\hline 3 & Control Systems for CPS & $\begin{array}{l}\text { Cloud Computing and Semantic } \\
\text { Web }\end{array}$ \\
\hline 4 & $\begin{array}{l}\text { Security \& Privacy in } \\
\text { CPS }\end{array}$ & Control Theory \\
\hline 5 & $\begin{array}{l}\text { Data Analytics for } \\
\text { Engineers } \\
\end{array}$ & Data Analytics for Engineers \\
\hline 6 & Embedded Systems & Digital Systems Architecture \\
\hline 7 & Real-Time Systems & Estimation Theory \\
\hline 8 & $\begin{array}{l}\text { Mobile and Ubiquitous } \\
\text { Computing }\end{array}$ & $\begin{array}{l}\text { Heterogeneous Multicore } \\
\text { Architectures }\end{array}$ \\
\hline 9 & $\begin{array}{l}\text { Cloud Computing and } \\
\text { Semantic Web }\end{array}$ & Image Processing \\
\hline 10 & $\begin{array}{c}\text { Intelligent Systems and } \\
\text { Robotics }\end{array}$ & $\begin{array}{c}\text { Image Processing and Computer } \\
\text { Vision }\end{array}$ \\
\hline
\end{tabular}

\section{NEXT STEPS}

Surveying the status and need for CPS education in the different participating countries in the MS@CPS project, in order to provide a strong base for an international CPS curriculum. Based on the lessons learned, which were surveyed within the partner countries, we will conduct an evaluation of a draft curriculum as a process of designing the program. This will set the focus on specific lectures to be conducted. It will also include the learning outcomes to be delivered, in order to ensure a high CPS curriculum standard. This process secures the indispensable building blocks of CPS education, while maintaining the needed individual flexibility, which provides students with a choice of specialization, and allows the necessary adjustments for national implementation in a given domain.

To help achieve this, a future oriented team will complement the learning outcomes focus, and practice focused pedagogy of MS@CPS. Many learning and teaching concepts have been introduced throughout the evolution of educational methodologies [7]. However, the specific implementation of learning concepts in a given domain or, more specifically, in single classes, remains an individual choice and subject to the free choice of the teacher, since they are the experts in the field and the ones who identify student needs. A pedagogy aligned to practical environments, as well as practical requirements, provides the necessary scaffolding and framing for learning and teaching. Therefore, the development of a practice-oriented MS@CPS pedagogy supports this by providing a framework comprising implicit guidelines for national implementations of the MS@CPS program. 


\section{CONCLUSION}

The MS@CPS project offers a great opportunity among the partners for collaboration to establish a modern master's degree program in CPS. The progress is promising to produce a distinguished program that makes a remarkable impact on partner countries. In spite of the different rules and regulations between countries in higher education, the project is moving forward in achieving its objectives.

The proposed methodology has produced an agreed-upon study plan that meets the market needs at the participating countries. The current consortium focus is on obtaining the necessary approvals to accredit the master program according to the national standards in Palestine, Jordan and Tunisia. The accreditation process will proceed in harmonized progress among the partners to ensure synchronized launch and inauguration of the master program in partner countries.

\section{ACKNOWLEDGMENT}

The ERAMSUS PLUS Key Action 2 (capacity building in higher education) has funded the work reported herein; project reference number: 598750 - EPP-1-2018-1-DE-EPPKA2CBHE-JP, which is gratefully acknowledged.

\section{REFERENCES}

[1] H. Gill, "From Vision to Reality: Cyber-Physical Systems", in HCSS National Workshop on New Research Directions for High Confidence Transportation CPS: Automotive, Aviation, and Rail, November 18-20, 2008. .

[2] National Academies of Sciences, E. and Medicine, A 21st Century Cyber-Physical Systems Education, Washington, DC: The National Academies Press. 106.

[3] Baheti, R. and H. Gill, Cyber-physical systems. The impact of control technology. 12(1): p. 161-166.

[4] Colombo, A.W., et al., Industrial cloud-based cyber-physical systems. The IMC-AESOP Approach. 22.

[5] Biggs, J., Teaching for Quality Learning at University. 2003.

[6] Dankov, P.I., et al. An interdisciplinary masters program in microwave communication focused on innovation: (Attracting and developing students' talent in challenging times). in 2011 IEEE EUROCON - International Conference on Computer as a Tool.

[7] Kuproyanov, R. and I. Kozlova. Developing Double Degree bilingual Master's program â€osocial work in industryâ€. in 2013 International Conference on Interactive Collaborative Learning (ICL).

[8] Starodubtseva, D.V., O.M. Zamyatina, and Y.O. Goncharuk. Curriculum design and development of master's educational programs in IT area (through the example of international development of master programs "Applied computing" and "Product life cycle technological process efficiency" of TEMPUS SUCCESS and ACES projects). in 2015 International Conference on Interactive Collaborative Learning (ICL).
[9] Barbosa, F., et al. European computer science master Curriculum Development methodology: management and research. in 2011 7th International Conference on Next Generation Web Services Practices.

[10] Proceedings of the 4th ACM SIGBED International Workshop on Design, Modeling, and Evaluation of Cyber-Physical Systems. Berlin, Germany: ACM.

[11] Zabasta, A., et al. Development of Industry Oriented Curricular on Cyber Physical Systems for Belarusian and Ukrainian Universities. in 2018 IEEE 6th Workshop on Advances in Information, Electronic and Electrical Engineering (AIEEE).

[12] Jon Patrick, W., et al., Systems Engineering of Cyber-Physical Systems: An Integrated Education Program.

[13] Cyber Physical Systems, Department of Computer Science, University of Oxford, UK. Available from: $\leq$ https://www.cs.ox.ac.uk/research/cyberphysical/index.html>. Master Program on Cyber-Physical and Social Systems (CPS ${ }^{2}$, International Track of the Master in Computer Science, Université de Lyon, France. Available from: $\leq$ https://www.emse.fr/ picard/cours/cps2/>.

[15] Master Mechatronic and Cyber-Physical Systems, Deggendorf Institute of Technology, Germany. Available from: $\leq$ https://www.th-deg.de/en/tc-cham-en/courses/mastermechatronic-and-cyber-physical-systems $>$.

[16] Industrial Informatics - Specialisation Industrial Cyber-Physical Systems, Hochschule Emden - Leer (University of Applied Sciences), Germany. Available from: $\leq$ https://www.hs-emdenleer.de/en/study/degree-courses/all-degree-courses/industrial-

\section{informatics $/>$.}

[17] The Professional Master of Embedded and Cyber-physical System, University of California, USA. Available from: $\leq$ https://mecps.uci.edu/ $>$.

[18] Master's Programme: Internet of Things and Cyber-physical Systems, HSE Tikhonov Moscow Institute of Electronics and Mathematics (MIEM HSE), Russia. Available from: miem.hse.ru/en/.

[19] Solutions. Palestinian ICT Private Sector 3-Year Strategy and Development Plan. 2012 Accessed on 13/8/2019]; Available from: http://www.lacs.ps/documentsShow.aspx?ATT_ID=5644.

[20] PITA. Comparative Study: The Palestinian Education System vs. The Needs of the Private ICT Sector, September 20142014 Access on 13/8/2019]; Available from: http://home.pita.ps/wp/wpcontent/uploads/files/Studies/comparative study the palestinian e ducation_system_vs_the needs_of the private_ict_sector.pdf.

[21] Available from: http://www.tunisiansmartcities.com.

[22] MS@CPS-Consortium. DeliverableD1.1 of MS@CPS Project: Evaluation of existing courses and identification of needed courses. 2019; Available from: http://blogs.uni-siegen.de/mscps/files/2019/04/D1.1-MS@CPS.pdf. 